\title{
A EDUCAÇÃO COMO MEIO PARA VENCER DESAFIOS IMPOSTOS AOS IDOSOS
}

Margarita Ana Rubin Unicovsky*

\section{Resumo}

$\mathrm{O}$ artigo discute a educação como meio para vencer os desafios impostos aos idosos pela idade e pela sociedade, propiciando-Ihes o aprendizado de novos conhecimentos e oportunidades para buscar seu bem-estar físico e emocional. Os programas educacionais para idosos vêm procurando atender a essas necessidades, trabalhando com diversos procedimentos pedagógicos, a fim de despertar a consciência critica para a busca do envelhecimento bem-sucedido. Por meio da educação continuada, esses programas têm possibilitado ao idoso, atualização, aquisição de conhecimentos e participação em atividades culturais, sociais, políticas e de lazer.

Descritores: educação; idoso; envelhecimento bem-sucedido

\begin{abstract}
This article discusses education as a means to face challenges imposed to the elderly by age and by society, thus allowing them to acquire new knowledge and obtain new opportunities to achieve physical and emotional well-being. Educational programmes for the elderly try to address these needs by working with several pedagogical procedures in order to awaken critical awareness in the search for a successful ageing. By means of continued education, these programmes have allowed the elderly to get up-to-date, acquire knowledge and participate in cultural, social, political, and leisure activities.

Descriptors: education; the elderly; successful ageing

Title: Education as a means to face challenges posed to the elderly
\end{abstract}

\section{Resumen}

El artículo discute la educación como medio de vencer los desafíos impuestos a los ancianos por la edad y por la sociedad, propiciándoles el aprendizaje de nuevos conocimientos $y$ oportunidades para buscar su bien estar físico y emocional. Los programas educativos para los ancianos procuran atender esas necesidades, trabajando con diversas propuestas pedagógicas, a fin de despertar una conciencia crítica para buscar un envejecimiento bien sucedido. Por medio de la educación continuada, esos programas posibilitan que los ancianos se actualicen; puedan adquirir conocimientos y participen de actividades culturales, sociales, políticas y de ocio.

Descriptores: educación; anciano; envejecimiento bien sucedido

Titulo: La educación como medio para vencer desafíos impuestos a los ancianos

\section{Introdução}

O momento atual suscita algumas reflexões para um tema que nos parece um dos mais importantes deste principio de século: o fato, amplamente provado, do aumento da expectativa de vida.

Embora grande parte de nossas aprendizagens seja considerada implícita, o que significa dizer que o meio ensina de maneira não deliberada, o processo ensino-aprendizagem vem sendo, historicamente, uma preocupação de estudiosos.

A inserção do idoso na sociedade, a mesma que o descarta pelo envelhecimento, tem encontrado na educação o eixo central para um novo aprendizado, o aprendizado do viver e do envelhecer, portanto, dos processos que caracterizam não só os envelhecimentos, sejam eles biológicos, psicológicos ou socioculturais, mas a dinâmica da própria aprendizagem.

O processo ensino-aprendizagem deve possibilitar ao idoso reflexões em torno do seu ambiente concreto, das suas vivências cotidianas, da sua realidade mais próxima. Essas reflexões conjuntas aumentam o nível de consciência dos problemas que afetam o coletivo. Isto ajuda a promover o sujeito, não ajustá-lo a realidades pré-programadas. A aprendizagem deve situar-se diretamente a partir da experiência, pois nenhuma necessidade é mais humana do que a de perceber o significado da própria vida. A elaboração e o desenvolvimento do conhecimento estão ligados ao processo de conscientização que "é sempre inacabado, continuo e progressivo; é uma aproximação crítica da realidade que vai desde as formas de consciência mais primitiva até a mais crítica e problematizadora e, conseqüentemente, criadora"(1:91). Nesse sentido, é preciso considerar qual ação pedagógica deve ser implementada para esse novo velho ator social. A aprendizagem passa a ser algo necessário e prazeroso, sendo desnecessário resistir na aprendizagem $^{(2)}$.

Tudo o que se aprende está relacionado ao sistema referencial da realidade. Aprende-se com a própria experiência. Indagação e sede de saber fazem parte da natureza humana. É necessário apenas acionar a capacidade de sentir para que se aprenda com satisfação. Ao aumentar a capacidade de absorver novas informações, estimula-se a percepção das relações entre um conjunto de dados e as estruturas de realidade pessoais, interiores e exteriores. Desse modo, cada fragmento de informação encontra o seu lugar adequado e amplia a integração do todo ${ }^{(2: 25)}$.

Isto será possível na medida em que a ação pedagógica desenvolvida leve em conta estímulos visuais, os comportamentos dos idosos (muitas vezes contidos),os diferentes ritmos sensório-motores, a história de vida pessoal, as possibilidades de interação e ampliação de conhecimentos, proporcionadas pela utilização de filmes, de passeios, de discussões, de atividades em grupo.

\section{Processo de ensino e aprendizagem no contexto do idoso}

Ao envelhecer, as pessoas confrontam-se com novos desafios e novas exigências. As limitações físicas são acrescidas àquelas que a sociedade coloca, como os preconceitos e os estereótipos, e o grande desafio é construir permanentemente o próprio caminho e desenvolver atitudes que as levem a superar suas dificuldades, integrando limites e possibilidades de conquistar mais qualidade de vida, que podem ser concebidas como um conjunto de condições dignas de existência.

As atividades relacionadas ao processo de envelhecimento são por sua natureza intrínseca, interdisciplinar, que envolvem diferentes áreas do conhecimento, na busca da melhoria da qualidade de vida e na necessidade de oferecer, nos processos de formação profissional e nas iniciativas educativas desenvolvidas junto a idosos, a oportunidade de discussão e de compreensão do processo de envelhecimento humano em suas múltiplas e relacionadas dimensões.

A educação, portanto, é um dos meios para vencer os

\footnotetext{
* Enfermeira. Professora Assistente da Escola de Enfermagem /UFRGS. Mestre em Educação.Doutoranda em Gerontólogia Biomédica PUC/RS.

E-mail do autor: mar.u@terra.com.br
} 
desafios impostos aos idosos pela idade e pela sociedade, propiciando-Ihes o aprendizado de novos conhecimentos e oportunidades para buscar seu bem- estar físico e emocional. Os programas educacionais para idosos vêm procurando atender a essas necessidades, trabalhando com diversos procedimentos pedagógicos, a fim de despertar a consciência crítica para a busca do envelhecimento bem-sucedido. O desafio que se apresenta é o de gerar motivação para que os idosos se interessem pelo que se pretende ensinar, de modo que empreguem esforço e dedicação na busca de criação de estratégias para reaprender a aprender, gerando um conhecimento que vai além de evitar ou atrasar doenças, que se caracteriza pela busca do engajamento pleno na vida. Por meio da educação continuada, esses programas têm possibilitado ao idoso atualização, aquisição de conhecimentos e participação em atividades culturais, sociais, políticas e de lazer.

Nesse sentido a ação genética vai buscar sua teoria visando a compreender as raízes do conhecimento, incluindo as mais diversas formas de aprendizagem. Em termos de estrutura de conhecimento nos leva a questionar quanto a importância de se traduzir as diversas fase da ciência na construção pessoal em diferentes fases da vida. Ao reportarmos à postura do empirismo no processo de aprendizagem devemos destacar que o sujeito é um ser passivo, receptor de informações prontas, que lhe servirão como bases e instrumentos de adaptação ao mundo em que vive, sendo uma realidade transmitida de maneira formal, pelo processo educativo. Assim, a inteligência passa a ter um papel de intermediar no processo de armazenar informações. Na educação de adultos, trabalhar em conjunto é o que impulsiona o processo de ensino e aprendizagem. O mestre e o aprendiz, juntos dividem suas expectativas e ansiedades, analisando formas de vencer as dificuldades que aparecem. Para esse trabalho, é importante que o mestre tenha conhecimento do desenvolvimento físico, psicológico e social do idoso, se conscientizando de que essa fase possui características peculiares. Além disso, é necessário que o mestre conheça os preconceitos e os estereótipos em relação à velhice, para que possa identificá-los e revê-los em sua ação.

A aprendizagem é um processo permanente de construção, que inicia ao nascer e se prolonga por todas as fases da vida. O indivíduo que acredita em suas potencialidades, por conseqüência da lógica a construção. Os idosos nesse processo apresentam um papel fundamental na construção e reconstrução do aprender, pois eles desencadeiam construções básicas de conhecimento de um ser autônomo, produtivo e extremamente cooperativo. Não podemos separar o processoensino aprendizagem sem vincular o idoso, pois ele completa todas as fases de conhecimentos do qual o homem cresce, se socializa, aprende e determina seus atos. É possível formarmos um sujeito autônomo frente a uma nova realidade educacional, pois a aprendizagem gera uma autonomia, inclui dentro do processo de desenvolvimento social o idoso como referencia viva de um aprendizado. O idoso precisa resgatar dentro deste processo uma ação participativa e efetiva, participando ativamente da sociedade em que vive. Ao passarmos este legado ao idoso estamos garantindo e reconhecendo sua participação não como obrigação, mas com uma atitude de cidadania, contribuindo de forma efetiva na melhoria da qualidade de vida. A contribuição do conhecimento transfere ao cidadão uma cooperação e pelo respeito mútuo, é necessário que proporcione um ambiente adequado ao seu desenvolvimento, de forma que possa construir-se como sujeito e autor de sua aprendizagem, este é o desafio que cabe inapelavelmente na sociedade. Precisamos resgatar o valor de uma educação continuada que seja pautada pela idéia de crescimento e democracia, que possibilite o desenvolvimento da capacidade intelectual e de uma estrutura cognitiva que permita a discussão corajosa dos problemas de seu tempo.

O aprendiz idoso necessita, com maior freqüência, obter êxito em suas tarefas para que se sinta motivado a continuar produzindo. O mestre, portanto, deve estar atento aos pequenos avanços apresentados pelo aprendiz e incentivá-lo a continuar. Outro aspecto importante a ser considerado pelo mestre é o de que o aprendiz idoso necessita de propostas claramente colocadas, sendo necessário o estabelecimento de objetivos precisos para que ele produza mais e sem fadiga.

Acima de tudo, o mestre tem que conhecer o interesse de seus aprendizes idosos, pois eles só se motivam e assimilam aquilo que for interessante. Não é exagero dizer que o aprendiz idoso "só faz aquilo que realmente quer", o que vai ao encontro de suas expectativas. O mestre dos programas para o idoso não se dedica, portanto, a transplantar os conhecimentos, para que o aprendiz enfrente todos os seus desafios. Deve ser companheiro do grupo, incentivando os aprendizes a lutar por melhores condições de vida.

Ao oferecer informações os mestres devem levar em conta um conjunto de princípios gerados no contexto da educação de idosos, cujo atendimento tende a favorecer a eficácia das suas iniciativas, qualquer que seja a idade ou nível educacional dos aprendizes ${ }^{(3)}$. Os princípios são os seguintes:

Processamento ativo: envolve dar oportunidades para aprender fazendo, ou seja dar oportunidades para a prática do que está sendo ensinado. Pessoas mais velhas são capazes de aprender tão bem quanto as mais jovens, desde que possam envolver e participar ativamente de programas estruturados, levando em conta os seus interesses e sua experiência anterior.

Retroalimentação e apoio sistemático: i nformações freqüentes sobre a qualidade e o progresso do desempenho facilitam o ajustamento e ajudam a aceitação do erro e da necessidade de correção. Essas informações devem ser fornecidas de forma sistemática e contigente.

Sistema de recompensas: o elogio e o reconhecimento podem funcionar como poderosos incentivos, principalmente se forem usados de modo sistemático contingente, no sentido de diferenciar padrões de desempenho.

Reconhecimento de conceitos: a o ensinar novos conceitos, isto é, expandir a base conhecimentos e habilidades préexistentes. A transferencia da aprendizagem é facilitada quando se inicia a partir do que os idosos já sabem.

Aplicabilidade direta: demonstrar os usos práticos e a aplicabilidade de um novo conceito e habilidade melhora a motivação de aprendizes idosos e aumenta a possibilidade de generalização do aprendido para situações novas. Nesse contexto é importante lembrar que a generalização dos conhecimentos teóricos para a prática não é automática. Em situações que exigem habilidades é importante criar, na situação de ensino, uma ampla quantidade de situações assemelhadas com aquelas que os aprendizes irão encornar na vida real.

Adaptação do contexto social: uma situação de aprendizagem não deve tornar-se uma oportunidade de confronto com a incapacidade, mas sim de capacitação das necessidades existentes. Deve-se evitar a competição em favor da cooperação e da aceitação. O apoio social dos companheiros é importante em qualquer idade, mas particularmente importante nos idosos. Por isso a aprendizagem em duplas ou em pequenos grupos é mais eficaz do que, a aprendizagem individual. Além disso, é necessário evitar que o idoso se molde a um contexto social improdutivo, como ocorre na maioria das vezes. Deve-se buscar motivações para promover um processo de mudança destes conceitos implícitos, iniciando uma nova construção direcionada para um idoso mais ativo e participativo.

Um contexto logístico adaptado: é necessário oferecer planos de trabalho adaptado às capacidades individuais dos idosos 
para compreender e fazer. É importante adotar estratégias personalizadas de ensino e acompanhamento. É interessante organizar o material a ser aprendido em unidades pequenas e significativas.

- Envolvimento com os objetivos: a participação é facilitada se os aprendizes têm oportunidades de participar da definição dos objetivos, a partir de seus interesses, necessidades, conhecimentos e habilidades.

Surge, então, a necessidade de investimento em práticas educativas que propiciem uma efetiva participação dos idosos como possuidores de potencial para produção de conhecimento e não como meros consumidores. Assim, desenvolvam sua sensibilidade em relação ao seu interior para que percebam, no seu cotidiano e na sua cultura de inserção, fontes inesgotáveis de conhecimento, trazendo benefícios não só individuais, como também para a própria comunidade de inserção.

É nesse contexto que surge a necessidade de projetos educacionais para o acesso ao conhecimento e para prevenir efeitos de exclusão, repensando a educação, pela consciência de que os idosos têm características singulares como grupo social, biológico e psicológico, que exigirá um novo estilo educativo, com diferentes objetivos, conteúdos e formas de estímulo à motivação. Desse modo, compete aos profissionais, que se dedicam a atividades educacionais com idosos, indagarem-se: até que ponto a metodologia utilizada, os conteúdos trabalhados e os objetivos pretendidos têm produzido motivação? É necessário profissional com formação direcionada ao idoso para organizar situações de aprendizagem com as características motivacionais de acordo com necessidades dos aprendizes para que estes construam novos conhecimentos e passem a ter um envelhecimento ativo e participativo no contexto social.

\section{Considerações finais}

O palpável adiamento da velhice merece ser considerado na fixação dos limites da idade para o tempo de atividade útil. Se a vida está sendo prolongada e evidentemente ampliado o ciclo de atividade produtiva dos indivíduos, nada mais justo e certo que dilatar o período de formação escolar e profissional, levando então a um idoso mais saudável e mais ativo.

As mudanças nas vias de educação para que o idoso se prepare a viver positivamente esta etapa de vida, visando às oportunidades de sua re-inserção no processo educacional formal, indicam um eixo norteador para novos aprendizados, de ligação entre educação e envelhecimento, expressões aparentemente incompatíveis, considerando que a educação sempre esteve ligada a crianças e jovens, de outro lado, de que o processo de envelhecimento é aprendido e, por isso, requer preparação. Esses requerimentos são desafiadores não só para os idosos, mas também para os docentes e para as instituições de ensino; sendo expressos nos conteúdos, na competência dos professores, na própria concepção de ensinoaprendizagem, preparando assim, idosos para um mundo de aceleradas mudanças, um mundo que consome idéias, sem limite de tempo e espaço, sem certezas. A preparação terá que ser para uma vida interativa, inconclusiva, com exigências cognitiva e instrumental, que considere aspectos éticos, afetivos, espirituais, criativos, de prazer e de alegria de viver.

É nesse contexto que surge a necessidade de projetos educacionais para o acesso ao conhecimento e para prevenir efeitos de exclusão, repensando a educação, pela consciência de que os idosos têm características singulares como grupo social, biológico e psicológico, que exigirá um novo estilo educativo, com diferentes objetivos, conteúdos e formas de estímulo à motivação. Desse modo, compete aos profissionais, que se dedicam a atividades educacionais com idosos, indagarem-se: até que ponto a metodologia utilizada, os conteúdos trabalhados e os objetivos pretendidos têm produzido motivação? É necessário profissional com formação direcionada ao idoso para organizar situações de aprendizagem com as características motivacionais de acordo com necessidades dos aprendizes para que estes construam novos conhecimentos e passem a ter um envelhecimento ativo e participativo no contexto social.

\section{Referências}

1. Mizukami MGN. Ensino: as abordagens do processo. São Paulo: Epu; 1986.

2. Ribeiro AEA. Educação: ampliando possibilidades de entendimento. Revista Saúde, Sexo e Educação, Rio de Janeiro 1997 abr/jun; 5(10):24-28

3. Knowles RL. Adult. The neglected learner. New York: Pergamon Press. In: Neri AL, Freire SA. Campinas (SP): Papirus; 2000.

Data de Recebimento: 12/12/2003

Data de Aprovação: 28/06/2004 